\title{
Sizing of a Hybrid Photovoltaic-Hydrokinetic Turbine Renewable Energy System in East Malaysia
}

\author{
Yonis .M. Yonis Buswig \\ Department of Electrical and \\ Electronic Engineering \\ Universiti Malaysia Sarawak \\ Kota Samarahan, Malaysia \\ byonis@unimas.my \\ Norhuzaimin bin Julai \\ Department of Electrical and \\ Electronic Engineering \\ Universiti Malaysia Sarawak \\ Kota Samarahan, Malaysia \\ jnorhuza@unimas.my
}

\author{
Azuka Affam \\ Department of Electrical and \\ Electronic Engineering \\ Universiti Malaysia Sarawak \\ Kota Samarahan, Malaysia \\ 18010014@siswa.unimas.my \\ Yi Sy Sim \\ Department of Electrical Engineering \\ Technology \\ Universiti Tun Hussein Onn Malaysia \\ Batu Pahat, Johor, Malaysia \\ sysim@uthm.edu.my
}

\author{
Al-Khalid Hj bin Othman \\ Department of Electrical and \\ Electronic Engineering \\ Universiti Malaysia Sarawak \\ Kota Samarahan, Malaysia \\ okhalid@unimas.my \\ Wahyu Mulyo Utomo \\ Department of Electrical Engineering \\ Technology \\ Universiti Tun Hussein Onn Malaysia \\ Batu Pahat, Johor, Malaysia \\ wahyu@uthm.edu.my
}

\begin{abstract}
The difficulties faced in the extension of conventional grid electricity to remote locations elicit increased application of renewable energy (RE) sources in such locations. In locations that are in proximity to rivers or streams, microhydro hybrid RE systems (HRES) are employed. Similarly, hybrid photovoltaic (PV) /battery configurations exist. Unfortunately, micro-hydro turbines require a minimum height/head and expensive civil works during installation. Hydrokinetic turbines (HKTs) eliminate the height/head requirement and greatly reduce necessary civil work by generating electricity using the kinetic energy of water flow in a river or stream. This study used a software, Hybrid Optimization of Multiple Energy Resources (HOMER), to simulate and obtain the optimal size and configuration of a hybrid PV/HKT/Battery storage system for Kampung Git in East Malaysia. Techno-economic comparison of the system is done with a PV/Battery and a standalone diesel generator (DG) system. The levelized cost of energy (LCOE) and the total net present cost (NPC) are the primary indices used for comparison purposes. The optimal configuration from simulations has 89.9 $\mathrm{kWp}$ of PV, two $3.5 \mathrm{~kW}$ HKTs and $132 \mathrm{kWh}$ of battery storage. Also, economic results obtained indicate that the LCOE of 1.21 $\mathrm{RM} / \mathbf{k W h}$ and NPC of RM 1,431,000 for the PV-HKT-battery configuration bested those for the PV-battery and standalone DG systems by $165 \%$ and $27 \%$ respectively. This optimal configuration is more environmentally friendly and highlights the role of the HKT in reducing battery usage and wear in addition to achieving lower LCOE and NPC values.
\end{abstract}

Keywords-hybrid system; HOMER; renewable energy, cost of energy (COE); net present cost (NPC); hydrokinetic turbine (HKT).

\section{INTRODUCTION}

Energy generation and management specialists in recent times have concentrated on the application of RE sources in different locations due to a myriad of reasons. A primary issue arises from environmentalists who have posited that, there are severe effects on the present and future by the pollution and degradation caused by using fossil fuels in power generation. A second issue is the predicted depletion of the conventional oil reserves in several decades. The study suggested that the world's oil reserves will be exhausted in
35 years. Other fossil fuels like coal and natural gas are projected to last 107 years and 37 years respectively [1].

The states of Sarawak and Sabah constitute East Malaysia. This part of Malaysia is yet to achieve the one hundred percent coverage by the electrical grid as proposed by the One Malaysia plan of 2015 [2]. The absence of grid electricity in Sarawak, Malaysia is predominant in the rural villages. The major challenge faced in extending grid electrification is the absence of access to these remote villages. This is further compounded by the sparse distribution of the villages and low population as related to cost. Some villages make use of diesel generators (DG) for temporary provision of electricity. This goes with increased emission of carbon into the atmosphere alongside high operation and maintenance (O\&M) cost for low income villagers

The huge RE potentials of Sarawak have been established as an alternative to DGs in the absence of the grid electricity [3]. The major RE sources at avail are photovoltaic (PV) and hydro sources. There is an abundance of rivers, leading to an estimated 10 megawatts (MW) micro-hydro potential. Microhydro systems have been set up in more than ten diverse locations in Sarawak [4]. The tropical climate of Sarawak ensures an average estimated daily irradiation of $5 \mathrm{kWh} / \mathrm{m}$ all year round [3]. Hence, PV has been applied in these rural dwellings for electricity generation.

The output power of RE sources shows a stochastic behavior. This is exemplified in PV where there is no output power at night. PV depends on intensity of light. Similarly, the power output of wind turbines and micro-hydro turbines are affected by wind speed and flow rate respectively [5]. This necessitated hybrid renewable energy systems. The hybrid system combines a storage element with one or more RE source. Different types of storage element have been used. The storage element may be a battery bank, pumped hydro storage, flywheel or other emerging technology. In the event of insufficient power from the RE sources to the load, the stored energy is used to balance the load requirement. The depleted storage is compensated for when there is enough power from the RE sources. 